\title{
Does Organizational Structure Moderate the Relationship between Strategic Planning and Competitive Advantage? A Study of Large Manufacturing Firms in Kenya
}

\author{
Jackson K. Maingi ${ }^{1}$, Zachary B. Awino ${ }^{1}$, Peter O. K'Obonyo ${ }^{1}$ \& Ganesh P. Pokhariyal ${ }^{2}$ \\ ${ }^{1}$ School of Business, University of Nairobi, Kenya \\ ${ }^{2}$ School of Mathematics, University of Nairobi, Kenya \\ Correspondence: Jackson K. Maingi, School of Business, University of Nairobi, P.O Box 30197, GPO Nairobi, \\ Kenya. E-mail: jmaingi@envisionstrategy.org
}

Received: March 11, 2019

doi:10.5539/ijbm.v14n5p141
Accepted: April 13, 2019

Online Published: April 18, 2019

\begin{abstract}
Several studies have been carried out in the past to find out how strategic planning and competitive advantage are connected and the causes of differences in competitive advantage among firms. Scholars have argued that competitive advantage can emanate from either internal or external sources and is usually in several forms which include; valuable resources, the position held within the industry, position within the marketplace, operating at lower costs than rival firms, differentiation, capabilities and dynamic capabilities. The debate on what causes differences in competitive advantage is still on. This study sought to establish the moderating effect of organizational structure on the relationship between strategic planning and competitive advantage of large manufacturing firms in Kenya. The study was underpinned by the competitive advantage typology of Michael Porter, the resource-based theory, dynamic capabilities theory, and the contingency theory. The study used a positivist research paradigm and a cross-sectional survey design. This was a census study from 124 large manufacturing firms in Kenya and data was collected from 122 of the firms representing a response rate of 98.4\%. The findings indicate that overall strategic planning has a statistically significant influence on competitive advantage and that organizational structure partially moderates the relationship between strategic planning and competitive advantage. The study recommended that once the strategy of the firm has been changed, an organization structure that fits the needs of the new strategy should be put in place. This is because in the absence of an organization structure that fits the needs of the firm, it will be difficult for the firm to achieve and sustain a position of competitive advantage.
\end{abstract}

Keywords: Strategic planning, competitive advantage, organizational structure, lower costs, differentiation, capabilities, dynamic capabilities

\section{Introduction}

\subsection{Research Problem}

There is no single explanation as to why firms attain competitive advantage and therefore different concepts have been used to explain the causes. The type of business level strategy applied, either low cost or differentiation, can generate competitive advantage (Porter, 1980, p. 35). A different conceptual foundation that focusses more on "capabilities of the firm states that a firm's ability to achieve and sustain competitive advantage is directly related to its firm-specific resources" (Barney, 1991, p. 105; Peteraf, 1993, p. 189; Rumelt, 1984, p. 561; Wernerfelt, 1984, p. 171). Hamel and Prahalad (1994) have argued that know-how, knowledge, intellectual assets and competencies are the key drivers of competitive advantage and as a result superior performance. Hamel and Prahalad (1994), agree with Pfeffer (1994) who has isolated human resources practices including organizational structure as the main driver of competitive advantage.

In most of the previous studies cited by the researcher, nearly all the elements contributing to competitive advantage have been studied in isolation or in some combination. Mutunga and Minja (2014, p. 1) "studied the generic strategies employed by Food and Beverage firms in Kenya and their effects on competitive advantage and established a positive relationship." Gowrie, Sreenivasan \& Govindan $(2012$, p. 29) studied "the critical success factors of sustainable competitive advantage of manufacturing firms in Malaysia and established the 
factors including cost leadership and differentiation”. Dirisu, Iyiola and Ibidunni (2013, p. 258) studied product differentiation as a tool of competitive advantage on the Unilever firm in Nigeria and found a positive relationship. The reviewed empirical literature indicates conceptual gaps because the studies cited so far did not consider how the strategic planning and competitive advantage relationship is influenced by organizational structure.

Studies to establish causes of competitive advantage have been done under various contexts. A study between "strategic planning and competitive advantage in Kenya's Information Communication Technology (ICTs) Small and Medium Enterprises (SMEs) sector" (Awino, 2013, p. 191) was carried out and a positive relationship established. Mutunga and Minja (2014, p. 1) carried out their study on "generic strategies employed by the Food and beverage sector in Kenya's manufacturing industry and established a positive relationship." Dirisu et al. (2013) carried out their study on one manufacturing firm, Unilever PLC Nigeria and established the existence of a positive influence of product differentiation on organizational performance. Gowrie et al. (2012) carried out their study on manufacturing firms as a whole in Malaysia. They did not distinguish between small, medium-sized or large firms. The study by Gowrie et al. (2012) managed to identify the critical factors contributing to sustainable competitive advantage. Chavunduka, Chimunhu \& Sifie $(2015$, p. 12) carried out a study on the "intensity of strategic planning and how it affects the performance of a firm using the case of Zimbabwe Mining Development Corporation and found a positive relationship." Kumar (2015, p. 64) "carried out a study on the correlation between strategic planning and firm performance based on European, Asian and American firms in India and found a positive association between strategic planning and performance regardless of size of the firm."

Flamholtz and Hua (2010, p. 222)) carried out a study in the USA "on searching for competitive advantage in the black box and established a positive relationship between organizational development factors and competitive advantage." Haron and Chellakumar (2012) carried out their study on efficiency performance of manufacturing firms in Kenya: evaluation and policies, from a sample based on all manufacturing firms in Kenya. Awino (2007) carried out a study on empirical investigation of selected strategy variables on firm performance: a study on supply chain management in large private manufacturing firms in Kenya.

There seems to be contextual gaps between the empirical studies cited by the researcher and this study. Firstly, the researcher has not come across a similar or nearly similar study to the one being studied that has been carried out on large manufacturing firms in Kenya. Secondly, the context for the current study is all large manufacturing firms in Kenya as per the Kenya Association of Manufacturers (KAM) 2015 Directory. Most of the other contexts studied were different and included the ICT sector in Kenya, food and beverage sector in Kenya, case study of one firm in Nigeria and other contexts in far off countries including the USA, India and Malaysia.

As for methodology used in some of the empirical literature reviewed; Awino (2013), Mutunga and Minja (2014), Gowrie et al. (2012), Awino (2007) and Manar (2014) used descriptive cross sectional surveys and on large samples. This same methodology was applied under the current study. On the other hand, Dirisu et al. (2013) used a case study of one firm, while Flamholtz and Hua (2010) sampled sixteen companies drawn from eight industries. All the scholars noted studied different topics from the one being studied and therefore, even for the scholars who had cross sectional surveys as their methodology, there still exists methodological gaps because of the subject of study.

As demonstrated, there remained unresolved issues along the conceptual, contextual and methodological spheres in the relationship among the variables being studied. The current study was on strategic planning being the predictor variable while competitive advantage was taken as the outcome variable. At the same time, organizational structure was taken as the moderating variable. The researcher has not identified a similar study undertaken that has considered the three variables together so far in the literature reviewed and even from the empirical studies documented. Most contexts of the studies nearer the one undertaken were from far away countries. This study addressed the gaps identified from the literature reviewed and attempted to answer the question: Is the relationship between strategic planning and competitive advantage of large manufacturing firms in Kenya affected by the organizational structure?

\subsection{Materials}

A number of studies have been done to find out how strategic planning and competitive advantage are connected and the causes of differences in competitive advantage among firms. Strategic planning has its roots in the concept of strategy. The term strategy has several meanings with no widely agreed upon universal meaning (Quinn, 1980, Mintzberg, Ahlstrand \& Lampel, 1998). A number of definitions have been put forward. Chandler (1962, p. 13) "described strategy as the determination of basic long term goals and objectives of an enterprise 
and the adoption of courses of action and the allocation of resources necessary for carrying out these goals." On his part, Andrews (1971, p. 18) "defined strategy as the pattern of major objectives, purposes or goals and essential policies or plans for achieving the goals, stated in such a way as to define what the business is in or is to be in and the kind of company it is or it is to be." Johnson, Scholes, and Whittington $(2008$, p. 9) have defined "strategy as the course and extent an organization charts out over the long term, which assists in attaining an edge over other organizations in a dynamic environment by reorganizing its resources and competencies with the objective of satisfying the expectations of shareholders." It has been recognized that in the Johnson, Scholes and Whittington (2008) definition, the contribution of strategy is "gradually compromised the more the relation between strategy and the purposes of an organization become more unclear with widening geographical and temporal dimensions and an ever-changing environment" (Bakir \& Todorovic, 2010, p. 1043).

Extending from the concept of strategy, different scholars and writers have described strategic planning in diverse but complementary ways. Wendy and Tushman (2005, p. 523) have described "the strategic planning process as consisting of three facets, these being strategic analysis, which incorporates the SWOT (Strengths, Weaknesses, Opportunities and Threats) analysis, strategic choices and strategic implementation.” The strategic analysis facet includes deciding the direction the organization will take regarding its vision, mission and goals (Kumar, 2015). Steiner (1979) has defined strategic planning as a systematic and to a certain extent-formalized effort of an organization to determine its essential purposes, policies, objectives and strategies. Ansoff (1970) has conceptualized strategic planning as being the means of trying to find a superior match between the products of an organization or technology and its increasingly unstable or turbulent markets.

There are two contrasting views in the process of strategic planning, the rational view and the political view. The rational view assumes the existence of a direct and straightforward means to an end relationship. "In the sequential rationality approach, strategic planning is deemed as a process of intended assessment and analysis, designed to ensure the achievement of the highest possible long-term advantage" (Mintzberg \& Lampel, 1999, p. 22). "The political view is concerned with the ways in which the parties involved can affect the process and outcomes of strategic decision-making either through the power they possess or through measures they take to exert influence" (Child, Elbanna \& Rodrigues, 2016, p. 1).

Strategic decisions are those, which have a significant impact on the organization and its long-term performance (Hickson, Buttler, Cray, Mallory \& Wilson, 1986, p. 311). "The political perspective focuses on how and why individuals, groups and organizations exercise power or accrue influence so as to shape the strategic decisions that are made on behalf of organizations" (Child et al., 2016, p. 1).

Every firm should have a distinct structure, which indicates its prevailing reporting relationship, image and internal politics (Kiptoo \& Mwirigi, 2014). Structure is not just represented by the chart of organization. Instead, it is represented by all the personnel, rankings, systems, processes, technology, culture, and other related elements that constitute an organization (Kavale, 2012). It seeks to establish the internal arrangement or pattern of authority, relationships, and communication in the organization (Mintzberg, 1979; Mathur \& Nair, 2015). Chandler (1962) considered the contingency relationship between the corporate strategy of a firm and its internal administrative structure and asserted that structure follows strategy and that it plays a major role in delivering the expected results.

The four constructs, which are key to the definition of organizational structure according to Mintzberg's (1979) include; formalization, centralization, specialization and integration. Formalization can be "defined as the extent to which established and formal rules and processes are applied in decision-making and relationships at the workplace" (Olson, Slater, Hult \& Tomas, 2005, p. 51). These established rules and processes are likely to enhance efficiency and reduce the costs of administration (Walker \& Ruekert, 1987). Firms which have highly formalized processes are said to be mechanistic while those with less formal processes are said to be organic.

Centralization occurs when authority to make decisions is tightly in the hands of top managers and very little of that authority is passed on to lower and middle level managers (Oslon et al., 2005). Centralizing activities may hinder opportunities for organizational learning. Specialization refers to "the degree to which duties and activities are shared out in an organization. Specialization not only provides a broad knowledge base but also precipitates intellectual latitude in the process of making decisions" (Collins, Hage \& Gill, 1988, p. 515). Organizations, which have more specialists, have a propensity to embrace more innovations. This is because these specialists have the expertise necessary to identify, take up and exploit new ways of doing things (Daugherty, Germain \& Drodge, 1995).

Integration refers to the strategic and operational connection of the processes of a business across groups with specialized functions. This connection is done using connecting devices, interdepartmental committees and 
functional teams (Mintzberg, 1979). Integration enables organizations to become more receptive and flexible through better means of communication and is necessary within complex firms in order to develop organizational capabilities (Lawrence \& Lorsch, 1967).

The overall objective of the study was to establish the effect of organizational structure on the relationship between strategic planning and competitive advantage of large manufacturing firms in Kenya. The specific objectives were to:

i. Determine the influence of strategic planning on the competitive advantage of large manufacturing firms in Kenya.

ii. Establish the effect of organizational structure on the relationship between strategic planning and competitive advantage of large manufacturing firms in Kenya.

The study to establish the moderating influence of organizational structure on the relationship between strategic planning and competitive advantage of large manufacturing firms in Kenya was anchored on various theories. Michael Porter's typology (theory) was the main theory. The other supporting theories included the contingency theory which underpins organizational structure, resource-based theory (RBT) and dynamic capabilities theory (DCT) which underpin competitive advantage (Barney, 1991, p. 99; Teece, Pisano \& Shuen, 1997, p. 509) and to some extent, organizational structure concepts.

The theory of competitive advantage by Porter (1990, p. 34) "proposes that states and businesses need to pursue policies that create goods of high quality for sale at high prices in the market. The competitive strategy is concerned with taking offensive and defensive actions that lead to the creation of a defendable position in an industry in order to cope successfully with competitive forces and create a superior return on investment."

Porter (1990) argues that the foundation for above-average performance within an industry is sustainable competitive advantage. Two ways of achieving competitive advantage have been identified; one is through cost leadership and the other is through differentiation. A third way which is also considered is focus.

Porter's competitive advantage theory has been criticized for the confusion between firms and nations. It has also been said that the theory is characterized by an environmental determinism and a linear cartesian point of view towards complex problems. This orientation assumes an enterprise is just the sum of its parts rather than being a complex, uncertain and ever-changing relationship amidst its parts. Beyond these criticisms, the theory of competitive advantage still stands strong. This study proposed that a firm can select a firm-level strategy like low cost or differentiation at the strategic planning stage. This firm-level strategy would lead to a review of the organizational structure. Once a structure that is suitable to employees is selected, the firm is in a position, by applying the selected firm-level strategy, to work towards attaining a sustainable competitive advantage position.

The contingency theory is founded on the presumption that there is no one form of organizational structure, which can be applied equally to different types of organizations. Instead, how effective an organization is depends on a fit between the technology use, its information system, the volatility of the environment, the organization size and the components of the organizational structure. "Van de Ven and Drazin (1985, p. 333) have explained the idea of fit in three different ways, that is, selection, interaction and systems approaches."

Once a fit is obtained between strategy and structure, the firm will be in a position to work towards attaining sustainable competitive advantage. During the time the firm is reviewing and changing its structure, it will have to ensure the type of structure selected can enable employees to adopt a strategically aligned behaviour and that they will be motivated and committed to work towards attaining the goals and objectives set out.

The basic research problem of contingency theory is that it is inherently dynamic. This is in spite of the concepts of fit used in actual research being not dynamic but static. Based on classical comparative studies, the concepts of fit presuppose a balanced or equilibrium position in both time and space. This equilibrium position has left a lacuna between applied ontology in contingency theory research and an ontology that is required for explaining the research problem. This study proposes that after a firm has determined the strategy to follow at the strategic planning stage, thereafter it will have to review and change its structure in order to align it to the new strategy.

According to Peteraf and Barney (2003, p. 309), "an organization will achieve a competitive advantage position when it generates additional economic benefit than its competitors in its product market. The RBT is based on two foundational assumptions about organization-based resources to clarify how sustained competitive advantage is generated" (Peteraf \& Barney, 2003, p. 309). The first assumption is that organizations own bundles of resources, which are different even when they are operating within a similar industry. The second assumption is that the resource differences may be sustained for a while due to the difficulty of buying and selling of resources across organizations. This difficulty in trading makes it possible for benefits from diverse resources to 
be sustained over a period of time (Barney \& Hesterly, 2012). Four conditions have to be simultaneously met for sustained competitive advantage (SCA) to exist and these are; the resources have to be Valuable, Rare, Inimitable and there should be good Organization (VRIO framework). An organization must be well organized in order to utilize the maximum competitive potential of the resources and capabilities it possesses (Barney \& Hesterly, 2012).

Some criticisms have been levelled against the resource-based theory. For example, methodological challenges keep occurring in the RBT literature. A pivotal matter that arises is how to measure resources mainly because a number of them are of an intangible nature (Godfrey \& Hill, 1995). Molloy, Chadwick, Ployhart \& Golden (2011) have picked up on the theoretical disconnect existing between RBT and the measuring of intangible resources and argued that this disconnect leaves some key questions un-addressed. This disconnect further undermines confidence in empirical tests that are supposed to support RBT and narrows the usefulness of future research. Molloy et al. (2011) have identified the gap through a content analysis of how scholars studied 186 intangibles in tests of RBT, which have recently been established.

This study posits that unique resources owned by the firm can be configured and used in a way that enables the firm to attain a competitive advantage position. It must be pointed out that the organizational structure will play a crucial part in the way the resources are configured and deployed if the firm is to attain and even sustain a competitive advantage position. The right

The Dynamic Capabilities Theory (DCT) is an extension of RBV and RBT (Teece et al., 1997, p. 509). "It underscores the deployment of the capabilities of the organization so as to attain higher-level performance. Dynamic capabilities (Teece et al., 1997, p. 509) emphasizes two main facets. The first facet is dynamic, which reflects the ability to have competencies renewed in order to agree with changes occurring in the business environment." The second facet is capabilities. This second facet emphasizes the crucial part played by strategic management in making organizations "to adapt, integrate and redesign internal and external organizational skills, resources and practical competencies" (Teece et al., 1997, p. 509). All this is done in order to counter the effects of an environment that is fast changing.

"In spite of the extensive utilization of the dynamic capabilities construct, a widely accepted definition has taken long to be developed" (Easterby-Smith, Lyles \& Peteraf, 2008, p. 2). Scholars from varied traditions have viewed dynamic capabilities differently depending on their background. "Zollo and Winter (2002, p. 339) for example have defined dynamic capabilities in terms of routines. On the other hand, Eisenhardt and Martin (2000, p. 1105) have defined dynamic capabilities in terms of processes whose nature varies with the degree of market dynamism taking the form of simple rules in high velocity environments." Williamson (1999) has criticized dynamic capabilities because of their lack of precise measurement and empirical grounding. "The poor understanding of dynamic capabilities coupled with the lack of a measurable model makes it difficult to explore how dynamic capabilities can be utilized in actionable managerial decision-making" (Pavlou \& El Sawy 2011, p. 239).

The study posits that knowledge and good organizational skills will be developed and deployed after the firm has determined its strategic direction. Such knowledge, which is embedded within the employees in the organizational structure, once implemented will ensure the resources of the firm are exploited to maximum advantage and therefore enable the firm to attain and even sustain a competitive advantage status.

\subsection{The Study Model}

The strategic planning and competitive advantage model used in the study is shown in Figure 1. From this model, strategic planning is the independent variable, competitive advantage is the dependent variable while organizational structure is the moderating variable. 


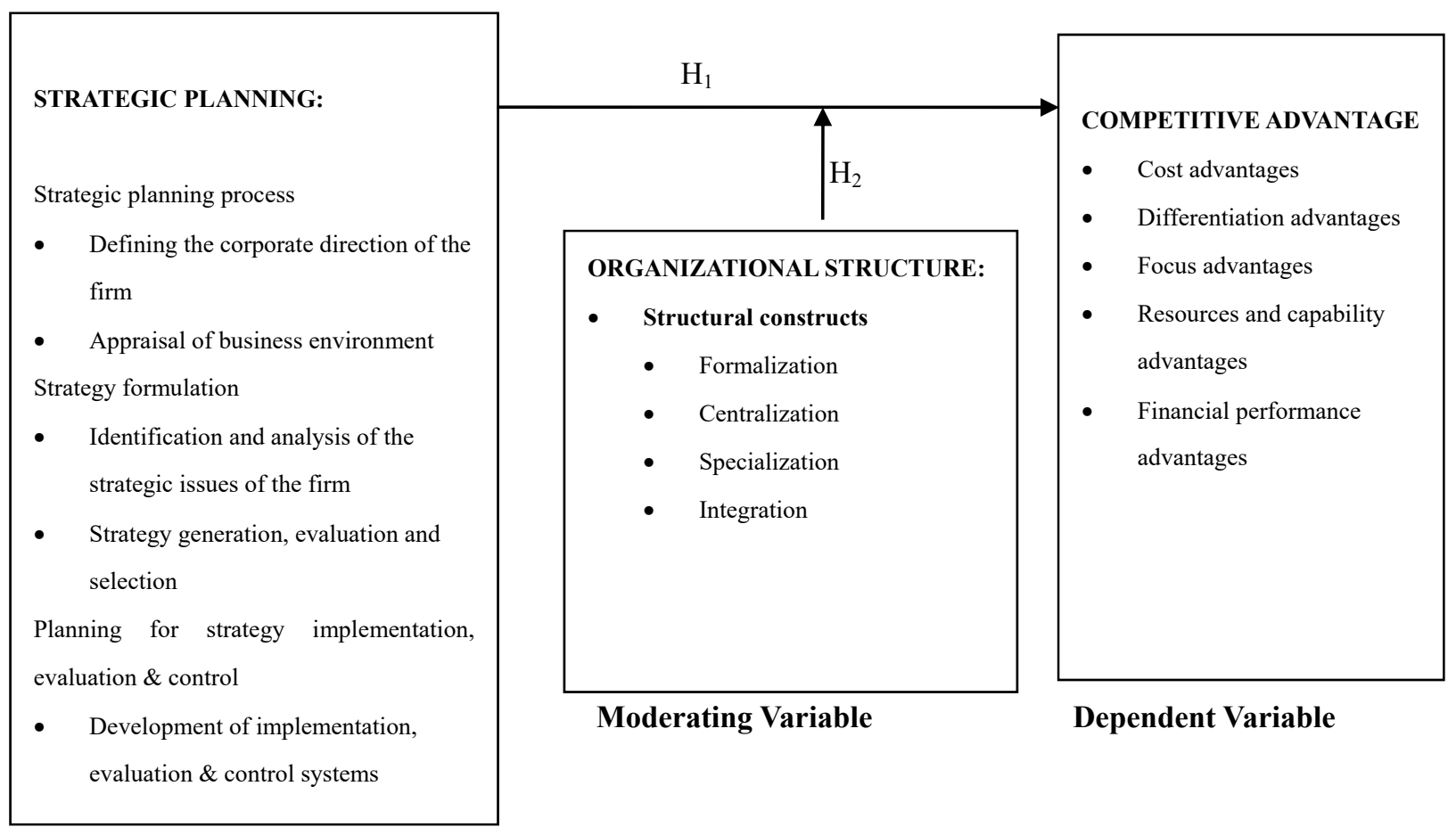

\section{Independent Variable}

Figure 1. Conceptual model

\subsection{Hypotheses of the Study}

From the study model, the relationships between the study variables were hypothesized as follows:

$\mathbf{H}_{1-}$ - Strategic planning significantly influences the competitive advantage of large manufacturing firms in Kenya.

$\mathbf{H}_{2}$ - Organizational structure significantly affects the relationship between strategic planning and competitive advantage of large manufacturing firms in Kenya.

\section{Method}

The philosophical foundation of this study was positivism. "By using the positivist paradigm, the researcher was guided by objectivity and could not influence the outcome of the study. The researcher was external to the process of collecting data and there was little he could do to alter the substance of the collected data" (Easterby-Smith, Thorpe \& Jackson, 2012, p.22). This study adopted a descriptive cross-sectional approach in order to establish the link between strategic planning and competitive advantage and the moderating effect of organizational structure in large manufacturing firms in Kenya. "A cross-sectional design involves collecting of data on more times than one and at more than one point in time with a view to having an amount of quantitative or qualitative data relating to two or even more than two variables, which are subsequently tested in order to establish any correlation between them" (Bryman \& Bell, 2011, p. 53).

The KAM Directory (2015) had only one measure of categorising manufacturing firms and that is turnover of the firm. Firms with a turnover of between Kshs 50 million and Kshs 150 million were categorised as small in size while firms with a turnover of between Kshs 151 million and Kshs 250 million were categorised as medium in size. Firms with a turnover of over Kshs 251 million were categorized as large in size. The total number of manufacturing firms as per KAM Directory (2015) excluding the service sector was 604. Out of this total, 299 firms are categorized as small, 181 firms categorized as medium while 124 firms were categorized as large in size. It is these 124 firms which formed the population of interest in this study.

The entire population of 124 large manufacturing companies were studied and therefore no sampling was necessary. The researcher chose a census study because it could enable the study to capture variability of responses. A census study also facilitated comparative analysis and ensured adequate representation, accuracy and reliability. Primary data was collected by using questionnaires while secondary data was extracted from 
information and documents maintained by the manufacturing firms. Reliability tests were performed to test quality of measurement while "validity tests were undertaken to test the quality of the questionnaire with improvements made where necessary (Sekaran \& Bougie, 2014, p. 225)." "In this study, the Likert-type scale (Saunders, Lewis \& Thornhill, 2012, p. 436) was used and respondents were requested to respond by choosing one option from statements usually given in five degrees of agreement or disagreement."

Out of the 124 firms selected for the study, 122 questionnaires were returned and upon further scrutiny, it was established that all of them had been completed well except in some few instances under the general information where some respondents had not responded to all the questions. The effective response rate was therefore $98.4 \%$. This response rate was good and compared well with other studies on large-scale manufacturing firms in Kenya carried out by other scholars in the past. Awino (2007) achieved a response rate of $65 \%$ and proposed that an average response rate of $65 \%$ for empirical studies is acceptable. Kidombo (2007) achieved a response rate of $64 \%$ while Magutu (2013) had a response rate of $75 \%$.

\section{Study Results}

The study sought to establish the effect of organizational structure on the relationship between strategic planning and competitive advantage of large manufacturing firms in Kenya. The results of the two hypotheses starting with hypothesis one $\left(\mathrm{H}_{1}\right)$ are given in the Tables that follow:

The first hypothesis was stated thus:

\section{$\mathrm{H}_{1}$ : Strategic planning significantly influences the competitive advantage of large manufacturing firms in Kenya.}

Table 1 gives the composite regression results of hypothesis one.

Table 1. Composite influence of Strategic planning on overall competitive advantage

\begin{tabular}{lllll}
\hline \multicolumn{2}{c}{ Model Summary } & & & \\
\hline Model & $\mathrm{R}$ & R Square & Adjusted R Square & Std. Error of the Estimate \\
1 & $.462^{\mathrm{a}}$ & .213 & .207 & .27895 \\
\hline
\end{tabular}

a. Predictors: (Constant), Strategic planning

\begin{tabular}{lllllll} 
ANOVA $^{\mathbf{a}}$ & & & & \\
Model & & Sum of Squares & $\mathrm{df}$ & Mean Square & $\mathrm{F}$ & Sig. \\
\hline 1 & Regression & 2.528 & 1 & 2.528 & 32.490 & $.000^{\mathrm{b}}$ \\
& Residual & 9.338 & 120 & .078 & & \\
& Total & 11.866 & 121 & & & \\
\hline
\end{tabular}

a. Dependent Variable: Competitive advantage

b. Predictors: (Constant), Strategic planning

Coefficients $^{\mathrm{a}}$

\begin{tabular}{|c|c|c|c|c|c|c|}
\hline \multirow[b]{2}{*}{ Model } & & \multicolumn{2}{|c|}{ Unstandardized Coefficients } & \multicolumn{2}{|l|}{$\begin{array}{l}\text { Standardized } \\
\text { Coefficients }\end{array}$} & \multirow[b]{2}{*}{ Sig. } \\
\hline & & $\mathrm{B}$ & Std. Error & Beta & $\mathrm{t}$ & \\
\hline & (Constant) & 1.543 & .482 & & 3.200 & .002 \\
\hline 1 & Strategic planning & .636 & .112 & .462 & 5.700 & .000 \\
\hline
\end{tabular}

a. Dependent Variable: Competitive advantage

The results in Table 1 indicate that strategic planning has a moderately weak but positive influence on competitive advantage $(\mathrm{R}=0.462)$. The coefficient of determination was 0.213 and this is an indication that strategic planning explained $21.3 \%$ of the variation in competitive advantage. The remaining $78.7 \%$ is to be explained by other factors not considered in this model.

The overall (ANOVA) model had a p-value which was less than 0.05 ( $\mathrm{p}$-value $=0.000, \mathrm{~F}=32.490$ ), and the results reveal a statistically significant model which implies that strategic planning influences competitive advantage. The results also indicate that strategic planning had a positive contribution with a beta value of 0.462 to a unit change in competitive advantage. The results further indicate statistically significant results with a $\mathrm{p}$-value of $0.000(\mathrm{t}$-value $=5.700)$ for strategic planning on competitive advantage. 
These results confirm hypothesis $\mathbf{H}_{\mathbf{1}}$ and lead to the conclusion that strategic planning has a significant influence on competitive advantage. The regression model based on the standardized beta coefficient is fitted thus: $\mathrm{CA}=1.543+0.462 \mathrm{SP}$.

The second hypothesis was stated thus:

\section{$\mathrm{H}_{2}$ : Organizational structure significantly affects the relationship between strategic planning and competitive advantage of large manufacturing firms in Kenya.}

To assess the moderating influence of organizational structure on the relationship between strategic planning and competitive advantage, the study used the Baron and Kenny (1986) method. Baron and Kenny (1986, p. 1174) posit that "moderation can only be supported if the interaction of the paths of the independent variable and the moderator variable is significant." Baron and Kenny (1986, p.1174) "proposed three steps be taken when testing for moderating effect. Step one involves testing the direct effect between the independent and the dependent variable. The results from this first step should be statistically significant for the researcher to proceed to the next step. Step two involves testing the effect of strategic planning and organizational structure on competitive advantage. Step three will involve testing the effect of strategic planning, organizational structure and the interaction term (between strategic planning and organizational structure) on competitive advantage.

The summarized results of the three moderating steps are shown in Table in Table 2 below:

Table 2. Summary of combined moderating effect of organizational structure

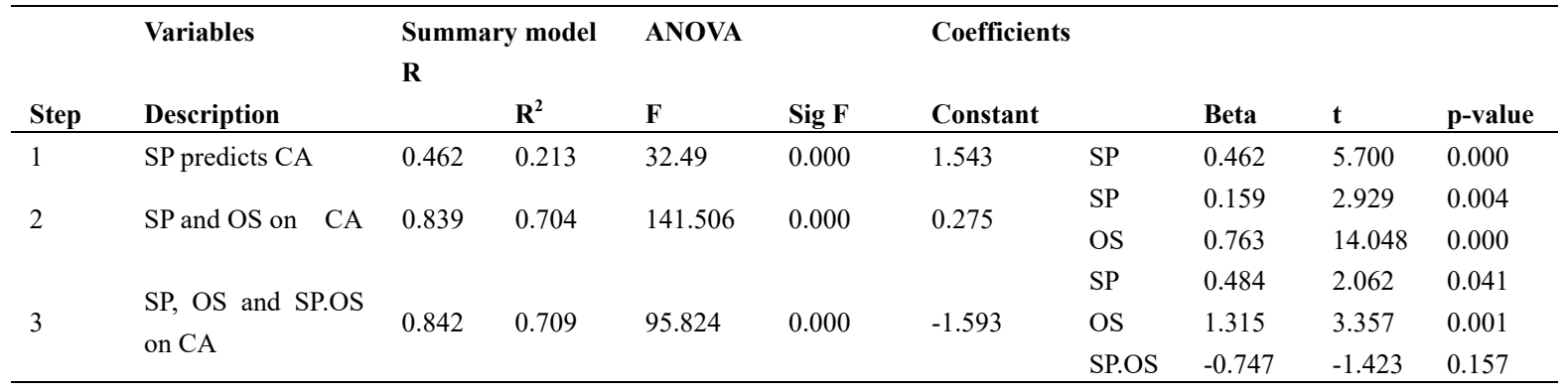

SP - Composite Strategic Planning

OS - Composite Organizational Structure

SP.OS - Interaction term Strategic Planning X Organizational Structure

CA - Composite Competitive Advantage

Under step one, $\mathrm{R}^{2}$ equals 0.213 indicating that strategic planning explains $21.3 \%$ of the variation in competitive advantage. The overall strength of the model in step one was $0.000(\mathrm{~F}=32.490)$. Furthermore, the p-value at $0.000(\mathrm{t}-\mathrm{value}=5.700)$ indicates significant results.

From step two, it is evident that the combined effects of strategic planning and organizational structure are far higher than for the single effect of strategic planning on competitive advantage. The coefficient of determination $\mathrm{R}^{2}$ for the combined effect is 0.704 implying that both strategic planning and organizational structure can explain $70.4 \%$ of the variation in competitive advantage. The overall strength of the combined model is much stronger with a significance of 0.000 but a very high F-value of 141.506 . The beta $(\beta)$ coefficients are also different under the combined value with strategic planning having a beta value of 0.159 while organizational structure has a beta value of 0.763 . Under the combined effect, the results were still statistically significant but had changed for the strategic planning variable. Under step one, the p-value under strategic planning was 0.000 (t-value $=5.700$ ) while in step two, the $\mathrm{p}$-value under strategic planning was $0.004(\mathrm{t}$-value $=2.929)$. The $\mathrm{p}$-value for organization structure in step two was 0.000 (t-value $=14.048)$.

Step three indicates the results after the introduction of the interaction term (SP.OS). The coefficient of determination $\mathrm{R}^{2}$ is higher than in the other two steps at 0.709 indicating that with the interaction term included, $70.9 \%$ of the variation in competitive advantage can be explained. The overall strength of the model remains quite strong with the introduction of the interaction term at a significance $p=0.000$ and an F-value of 95.824. However, this F-value is lower than in step two where it was 141.506 . The constant term $\left(\beta_{0}\right)$ has also changed into a negative $(-1.593)$ after the introduction of the interaction term. In the first step, the constant factor was 1.543 while in step 2, it was 0.275 . 
Both strategic planning and organizational structure have retained their statistically significant results after the introduction of the interaction term at $0.041(\mathrm{t}$-value $=2.062)$ for strategic planning and $0.001(\mathrm{t}$-value $=3.357)$ for organizational structure. However, the interaction term shows non-statistically significant results with a $\mathrm{p}$-value of 0.157 (t-value $=-1.423)$.

There are three decision rules to checking whether moderation has occurred (Baron \& Kenny, 1986, p. 1174). These rules are; "one, after adding the interaction term, if there is a significant change in $\mathrm{R}^{2}$ as well as significant effect by the new interaction term, then moderation is occurring. Decision rule number two is if the predictor and moderator are not significant with the interaction term added, then complete moderation has occurred. Decision rule number three is that if the predictor and moderator are significant with the interaction term added, then moderation has occurred, however, the main effects are also significant."

In the study model, there was a significant change in $\mathrm{R}^{2}$ as compared to the first step, but the change was not as big as compared to the second step (with interaction term, $\mathrm{R}^{2}$ was 0.709 , while under step one, $\mathrm{R}^{2}$ was 0.213 while in step two, $\mathrm{R}^{2}$ was 0.704 ). After the introduction of the interaction term, there was a significant change in the F-value (95.824 with interaction term, 141.506 with the predictor [SP] and moderator [OS] and 32.49 with strategic planning only). This implies that the first condition for a moderation effect to exist was met. The other condition which has been met is the third one. Under this condition, the predictor (SP) and moderator (OS) have to be significant with the interaction term added and the main effects are also significant. Strategic planning produced statistically significant results with a $\mathrm{p}$-value of $0.041(\mathrm{t}$-value $=2.062)$ while organizational structure had a p-value of $0.001(\mathrm{t}$-value $=3.357)$. The interaction term produced statistically non-significant results with a $\mathrm{p}$-value of 0.157 (t-value $=-1.423)$.

The overall results from hypothesis two were therefore that partial moderation had taken place. These findings were sufficient to support the hypothesis, which states that, organizational structure significantly affects the relationship between strategic planning and competitive advantage of large manufacturing firms in Kenya.

\section{Discussion of Results and Conclusion}

\subsection{Discussion of Results}

This study sought to establish the effect of organizational structure on the relationship between strategic planning and competitive advantage of large manufacturing firms in Kenya. Two specific objectives had been formulated to test the relationships between the three variables. Against the two specific objectives were developed two hypotheses for further testing. The results indicated a statistically significant relationship on the first hypothesis which stated that strategic planning influenced the competitive advantage of large manufacturing companies in Kenya. On the second hypothesis that was testing whether organizational structure significantly affected the relationship between strategic planning and competitive advantage of large manufacturing firms in Kenya, partial moderation was established.

It has been argued that "the fit between strategy, structure, environment and the capacity of the firm should be nurtured in order to generate a strategic fit" (Johnson et al., 2008, p. 434). The results of this study tend to agree with this assertion because if organizational structure is not considered, then the results obtained between strategic planning and competitive advantage are far lower than when the component of organizational structure is considered and dealt with adequately. In this study, the effect of organizational structure when combined with strategic planning was far stronger than that from strategic planning alone.

The findings confirm the assertions by Grant (1998) that the main structure of a firm is one of the fundamental ways used by strategists to try and position the firm in order to implement the strategy in a way that balances internal efficiency and effectiveness. The results further tend to confirm that when strategy is changed, then what everyone does in the organization should be changed (Ansoff, 1965). This is because of the big impact organizational structure has on the competitive advantage of an organization.

The results also lend their support to the assertion by Chandler (1962), that structure follows strategy. It has already been indicated that when strategic planning and organizational structure are taken together, organizational structure has a stronger effect. This would seem to suggest that it would be a poor exercise to develop a strategic plan for an organization and fail to consider whether the structure in place was sufficient to assist in implementing the plan. The results also confirm the studies by Manar (2014, p. 35) who concluded, "That all the dimensions of structure were related to organizational commitment. It is through commitment to the organization's ideals that higher levels of competitiveness are achieved." 


\subsection{Conclusion}

The objective of the study was to establish the effect of organizational structure on the relationship between strategic planning and competitive advantage of large manufacturing firms in Kenya. Two hypotheses were developed to test this relationship. Hypothesis one was on whether strategic planning significantly influenced competitive advantage while hypothesis two was whether there was a moderating influence of organizational structure on the relationship between strategic planning and competitive advantage. The results obtained indicated that strategic planning influenced competitive advantage and that organizational structure partially mediates the relationship between strategic planning and competitive advantage. This is after two of the conditions necessary for a partial moderation to take place suggested by Baron and Kenny (1986) were fully met. These findings inform senior managers of large manufacturing firms that they need to change the organizational structure if they want to maximize on their results from the strategic planning process after developing new strategies.

The results of the study contributed to strengthening the existing body of literature confirming empirically that strategic planning influences competitive advantage of large manufacturing firms both directly and indirectly through the moderating variable. The anchoring theory/typology of Michael Porter's competitive advantage (1990) was confirmed. Porter (1990) has argued that the foundation for above average performance within an industry is sustainable competitive advantage, which can be achieved through cost leadership, differentiation or focus. The contingency theory was used to support organizational structure. The theory is founded on the presumption that there is no one form of organizational structure which can be applied to different types of organizations (Van de Ven \& Drazin, 1985). Instead, how effective an organization is depends on a fit between the technology use, its information system, the volatility of the environment, the organization size and the components of the organizational structure. In this study, organizational structure was operationalized using four constructs, these being, formalization, centralization. Specialization and integration. The results of the study were that there was partial moderation of the relationship between strategic planning and competitive advantage. In fact, there was a significant relationship between organizational structure and competitive advantage. These findings enhance the importance of having the right organizational structure if large manufacturing firms are to attain a position of competitive advantage. This study has helped in advancing the contingency theory as it relates to large manufacturing firms in Kenya.

The results given above notwithstanding, the study lacked comparison of other similar studies done either locally or abroad. It was therefore difficult to generalize on the study findings. Besides, the study utilized a cross-sectional survey because it was the most appropriate at the time. Cross-sectional studies however, do not allow for causal effects on the observed relationships over time and therefore could not give actual relationships that exist between strategic planning, organizational structure and competitive advantage of large manufacturing firms in Kenya. Future researchers could consider using approaches like longitudinal studies. Such studies can give the change in competitive advantage of large manufacturing firms over time. The study was designed to capture the response of one respondent per firm at a given point in time.

Using a single respondent for research has limitations because of the possibility of the common method bias. Although the respondents are thought and expected to give objective responses, they could have their own biases and perceptions, which could lead to misleading and subjective responses. It therefore becomes difficult to tell whether the perception was the respondent's or the organization's. Future researchers could consider using multiple respondents in order to compare views of other respondents in the firm.

The study focused on large manufacturing firms. It did not consider small and medium-sized manufacturing firms. The small to medium-sized manufacturing firms may be faced with different challenges as compared to large manufacturing firms. It may therefore be difficult to generalize the results obtained from the large manufacturing firms to the small to medium-sized firms. The study was also focussed on the manufacturing sector, which mainly deals in goods. Similar studies could be carried out on the small to medium-sized manufacturing firms as well as in other sectors of the economy including banks and insurance companies.

Finally, the study operationalized competitive advantage on five perspectives of cost advantages, differentiation advantages, focus advantages, resources and capability advantages and financial performance advantages. These indicators are highly business specific. The study did not consider environmental and social aspects as indicators. These could cover areas like legality and freedom of action among others, which are exposures on environmental and social nature. Future studies could consider including environmental and social aspects as indicators of competitive advantage. 


\section{Acknowledgements}

I wish to convey my special sincere gratitude to my supervisors, Prof. Zachary B. Awino, Prof. Peter O. K'Obonyo and Prof. Ganesh P. Pokhariyal for their tremendous support, guidance and encouragement as I did this study. I would like to thank them for being patient with me during the many hours of consulting them that enabled me to reach the final stages of the study. The many hours they spent critiquing, correcting and giving me wise counsel on how to proceed have enabled to get this far.

\section{References}

Andrews, K. R. (1971). The Concept of Corporate Strategy. Homewood, IL: Dow Jones-Irwin.

Ansoff, H.I. (1970). Does planning pay? Long Range Planning, 3(2), 2-7.

Ansoff, I. (1965). Corporate strategy. McGraw Hill, New York.

Awino, Z. B. (2007). Strategic management: An empirical investigation of selected strategy variables on firm performance: a study of supply chain management in large private manufacturing firms in Kenya. Prime Journals, 1(1), 9-18.

Awino, Z. B. (2013). Strategic planning and competitive advantage of ICT small and medium enterprises in Kenya. Business and Management Horizons (Microthink Institute), 1(1), 191-204.

Bakir, A., \& Todorovic, M. (2010). A hermeneutic reading into 'what strategy is; Ambiguous means-end relationship. The Qualitative Report, 15(5), 1037-1057.

Barney, J. B. (1991). Firm resources and sustained competitive advantage. Journal of Management, 17(1), 99-120.

Barney, J., \& Hesterly, W. (2012). Strategic Management and Competitive Advantage: Concepts and cases (4th ed.). New Jersey: Pearson.

Baron, R. M., \& Kenny, D. A. (1986). The moderator-mediator variable distinction social psychological research: Conceptual, strategic and statistical considerations. Journal of Personality and Social Psychology, 51, 1173-1182.

Bryman, A., \& Bell, E. (2011). Business Research Methods ( $3^{\text {rd }}$ Ed.). Oxford University Press. Great Clarendon Street, Oxford.

Chandler, A. D. (1962). Strategy and Structure. Chapters in the history of the American industrial enterprise. Cambridge, MA: MIT Press.

Chavunduka, D., Chimunhu, P., \& Sifie, O. (2015). Strategic Planning intensity and firm performance: A case of Zimbabwe mining development corporation. European Journey of Business and Management, 7(5), 12-18.

Child, J., Elbanna, S., \& Rodrigues, S. (2016). The Political Aspects of Strategic Decision Making. The Handbook of Decision Making.

Collins, P. D., Hage, G., \& Hull, F. M. (1988). Organizational and technological predictors of change in automaticity. Academy of Management Journal, 31(3), 512-543.

Daugherty, P. J., Germain, R., \& Drodge, C. (1995). Predicting EDI technology: Adoption in logistics management: The influence of context and structure. Logistics and Transportation Review, 31(4), 309-324.

Dirisu, J. I., Iyiola, O., \& Ibidunni, O. S. (2013). Product differentiation: a tool of competitive advantage and optimal organizational performance (a study of Unilever Nigeria PLC). European Scientific Journal, 9(34), 258-281.

Easterby-Smith, M., Lyles, P., \& Peteraf, M. (2008). Dynamic capabilities: current debates and future directions. British Journal of Management, 609. 1-8.

Easterby-Smith, M., Thorpe, R., Jackson, P. (2012). Management Research (4th ed.). SAGE Publications Ltd., London.

Eisenhardt, K. M. \& Martin, J. A. (2000). Dynamic capabilities: what are they? Strategic Management Journal, $21,1105-1121$.

Flamholtz, E., \& Hua., W. (2010). Searching for competitive advantage in the black box. European Management Journal, 21(2), 222-236.

Gibbons, P. T., \& O’Conner, T. (2005). Influences on strategic planning processes among Irish SMEs. Journal of Small Business Management, 43(2), 170-186. 
Godfrey, P. C., \& Hill, C. W. L. (1995). The problem of unobservables in strategic management research. Strategic Management Journal, 16, 519-533.

Gowrie, V., Sreenivasan, J., \& Govindan, M. (2012). Critical success factors of sustainable competitive advantage; a study in Malaysian manufacturing industries. International Journal of Business and Management, 7(22), 29-45.

Grant, R. (1998). Contemporary Strategy Analysis: Concepts, Techniques, Applications. Blackwell Publications: United States.

Hamel, G., \& Prahalad, C. (1994). Competing for the Future, Harvard University Press, Boston.

Haron, M., \& Chellakumar, J. A. A. (2012). Efficiency performance of manufacturing companies in Kenya: Evaluation and policies. International Journal of Management Business Research, 2(3), 233-242.

Hickson,. D. J., Butler, R. J., Cray, D., Mallory, G. R., \& Wilson, D. C. (1986). Breaking the bounds of organization in strategic decision making. Journal of Human Relations, 39(4), 309-331.

Johnson, G., Scholes, K., \& Whittington, R. (2008). Exploring corporate strategy (8th ed.). London, UK: Prentice-Hall.

Kavale, S. (2012). The connection between strategy and structure. International Journal of Business and Commerce, 1(6), 59-70.

Kenya Association of Manufacturers. (2015). The Kenya Association of Manufacturers and Exporters Directory Nairoib. Adafric Communications Limited.

Kidombo, H. J. (2007). Human resource strategic orientation, firm's commitment and firm performance in large private manufacturing firms in Kenya (Unpublished PhD Thesis). University of Nairobi, Nairobi.

Kiptoo, J. K., \& Mwirigi, F. M. (2014). Factors that influence strategic planning process in organizations. IOSR Journal of Business and Management, 16(6), 188-195.

Kumar, P. (2015). Correlation between strategic planning and firm performance. International Journal of Management and Business studies, 5(2), 64-75.

Lawrence, P. R., \& Lorsch, J. W. (1967). Organization and Environment: Managing Differentiation and Integration. Homewood, IL: Richard D. Irwin.

Magutu, P. O. (2013). Supply Chain Strategies, Technology and Performance of Large Scale Manufacturing Firms in Kenya. (Unpublished PhD Thesis), University of Nairobi, Kenya.

Manar, I. A. (2014). The impact of organizational structure on organizational commitment: a comparison between public and private sector firms in Jordan. European Journal of Business Management, 6(12), 30-37.

Mathur, P., \& Nair, M. (2015). Organizational structure, a key driver to competitive advantage. International Journal of Management and Commerce Innovations, 3(2), 348-356.

Mintzberg, H. (1979). The Restructuring of Organizations: A Synthesis of the Research. Prentice Hall, Engelwood Cliffs, NJ.

Mintzberg, H., \& Lampel, J. (1999). Reflecting on the strategy process. Sloan Management Review, Spring, $1999,21-30$

Mintzberg, H., Ahlstrand, B. and Lampel, J. (1998). Strategy Safari: A Guided Tour Through the Wilds of Strategic Management. New York: The Free Press.

Molloy, J., Chadwick, C., Ployhart, R., \& Golden, S. (2011). Making intangibles tangible. A multidisciplinary critique and validation framework. Journal of Management, 37, 1496-1518.

Mutunga, S. L., \& Minja, D. (2014). Generic strategies employed by food and beverage firms in Kenya and their effects on sustainable competitive advantage. International Journal of Business and Management Review, 2(6), 1-15.

Oslon, E. M., Slater, S. F., Hult, G., \& Tomas, M. (2005). The performance implications of fit among business strategy, marketing organization and the strategic behaviour. Journal of Marketing, 69, 49-65.

Pavlou, P., \& El Sawy, O. (2011). Understanding the black box of dynamic capabilities. Decision Science, 42(1), 239-272.

Peteraf, M. (1993). The cornerstone of competitive advantage: A resource-based view. Strategic Management 
Journal, 14, 179-191.

Peteraf, M., \& Barney, J. (2003). Unravelling the resource-based tangle. Managerial and Decision Economics, 24(4), 309-323.

Pfeffer, J. (1994). Competitive Advantages Through People. Boston, M.A: Havard Business School Press.

Porter, M. E. (1980). Competitive Strategy: Techniques for Analyzing Industries and Competitors. New York. The Free Press.

Porter, M. E. (1985). Competitive Advantage. New York: Free Press.

Porter, M. E. (1990). The Competitive Advantage of the Nations. New York: Free Press.

Porter, M. E. (1991). Towards a dynamic theory of strategy. Strategic Management Journal, 12, 95-117.

Quinn, J. B. (1980). Strategies for Change: Logical incrementalism. Homewood, IL: Irwin.

Rumelt, R. P (1984). Towards a strategic theory of the firm. In R. Lamb (Ed). Competitive Strategic Management (pp. 556-570). Eaglewood Cliffs, NJ: Prentice-Hall.

Saunders, M., Lewis, P., \& Thornhill, A. (2012). Research Methods for Business Students (6th ed.). Harlow: Prentice Hall, Pearson Education Limited.

Sekaran U. \& Bougie R. (2014). Research Methods for Business: A Skill-Building Approach (6 ${ }^{\text {th }}$ ed.). John Wiley $\&$ Sons Ltd.

Steiner, G. A. (1979). Strategic Planning. What every manager must know. New York: Free Press.

Teece, D. J., Pisano, G., \& Shuen, A. (1997). Dynamic capabilities and strategic management. Strategic Management Journal, 18(7), 509-533.

Van de Ven, A. H., \& Drazin, R. (1985). The concept of fit in contingency theory. Research in Organizational Behaviour, 7(4), 333-365.

Walker, O. C., \& Ruekert, R. W. (1987). Marketing role in the implementation of business strategies: A critical review and conceptual framework. Journal of Marketing, 51, 15-33.

Wendy, K. S., \& Tushman, M. L. (2005). Managing Strategic Contradictions: a top management model for managing innovation streams. Organization Science, 16(5), 522-536.

Wernerfelt, B. (1984). The resource-based view of the firm. Strategic Management Journa, 5(2), 171-180.

Williamson, O. E. (1999). Strategy research: governance and competence perspectives. Strategic Management Journal, 20, 1087-1108.

Zollo, M., \& Winter, S. (2002). Deliberate learning and the evolution of dynamic capabilities. Organization Science, 13, 339-351.

\section{Copyrights}

Copyright for this article is retained by the author(s), with first publication rights granted to the journal.

This is an open-access article distributed under the terms and conditions of the Creative Commons Attribution license (http://creativecommons.org/licenses/by/4.0/). 